\title{
Using Facebook Ads Data to Assess Gender Balance in STEM: Evidence from Brazil
}

\author{
Carolina C. Vieira \\ Max Planck Institute for Demographic Research \\ Rostock, Germany \\ coimbravieira@demogr.mpg.de
}

\author{
Marisa Vasconcelos \\ IBM Research \\ São Paulo, Brazil \\ marisaav@br.ibm.com
}

\begin{abstract}
Workforce diversification is essential to increase productivity in any world economy. In the context of the Fourth Industrial Revolution, that need is even more urgent since technological sectors are men-dominated. Despite the significant progress made towards gender inequality in the last decades, we are far from the ideal scenario. Changes towards equality are too slow and uneven across different world regions. Monitoring gender parity is essential to understand priorities and specificities in each world region. However, it is challenging because of the scarcity and the cost to obtain data, especially in less developed countries. In this paper we study how the Facebook Advertising Platform (Facebook Ads) can be used to assess gender imbalance in education, focusing on STEM (Science, Technology, Engineering, and Mathematics) areas, which are the main focus of the Fourth Revolution. As a case study, we apply our methodology to characterize Brazil in terms of gender balance in STEM as well as to correlate the results using Facebook Ads data with official Brazilian government numbers. Our results suggest that even considering a biased population where the majority is female, the proportion of men interested in some majors is higher than the proportion of women. Within STEM areas, we can identify two different patterns. Life Science and Math/Physical Sciences have female dominance, Environmental Science, Technology, and Engineering majors are still concentrated towards men. We also assess the impact of educational level and age on the interest in majors. The gender gap in STEM increases with the women's educational level and age, as confirmed by official data in Brazil.
\end{abstract}

\section{CCS CONCEPTS}

- Information systems $\rightarrow$ Web and social media search; Social networks; • Networks $\rightarrow$ Online social networks; $\bullet$ Applied computing $\rightarrow$ Sociology.

\section{KEYWORDS}

Social media, Social networks, Sociology

ACM Reference Format:

Carolina C. Vieira and Marisa Vasconcelos. 2021. Using Facebook Ads Data to Assess Gender Balance in STEM: Evidence from Brazil. In Companion

This paper is published under the Creative Commons Attribution 4.0 International (CC-BY 4.0) license. Authors reserve their rights to disseminate the work on their personal and corporate Web sites with the appropriate attribution.

WWW'21 Companion, April 19-23, 2021, Ljubljana, Slovenia

(c) 2021 IW3C2 (International World Wide Web Conference Committee), published under Creative Commons CC-BY 4.0 License.

ACM ISBN 978-1-4503-8313-4/21/04.

https://doi.org/10.1145/3442442.3453456
Proceedings of the Web Conference 2021 (WWW'21 Companion), April 1923, 2021, Ljubljana, Slovenia. ACM, New York, NY, USA, 9 pages. https: //doi.org/10.1145/3442442.3453456

\section{INTRODUCTION}

In the past decades, several studies and initiatives discussed the problem of gender inequality in areas such as health, education, economy, and politics. Despite the progress in some areas, we are moving too slow to achieve full parity in the near future [6]. For instance, education still faces old challenges such as increasing girls' access to primary school, as well as new ones, such as preparing women to be better qualified to be included in the so-called Fourth Industrial Revolution.

In that future scenario, areas related to STEM (Science, Technology, Engineering, and Math) are expected to have a growing demand [23]. However, currently, there is a large gender gap due to a lower presence of women who graduate and follow careers related to those fields $[8,24]$. Diverse factors from family encouragement to cultural perceptions (e.g., stereotypes) were pointed out as possible causes women to avoid STEM subjects [5].

Other factors are specific in some countries, which makes this kind of study very complex on a global scale. Worldwide surveys, for example, are costly and usually restricted to developed countries [14]. Towards filling this gap, our paper presents a different methodology to assess gender inequality in STEM subjects by examining the potential of using online sources of data, particularly data provided by the Facebook Advertising Platform (Facebook Ads).

Facebook Ads data aggregates information about Facebook users by their demographics and/or interests. This data has been used in many contexts, including the study of gender gaps. A recent work [7] correlates Facebook data to other gender inequality indexes on a large scale across multiple countries. Inspired by it, we focus on analyzing the gender balance in STEM using Brazil as a case study. Brazil is the third country with more Facebook users and women represent $54 \%$ of this audience ${ }^{1}$. Brazil is also an interesting scenario since women constituting $49 \%$ of the researcher population [13] while some STEM fields, such as Computer Science, are still underrepresented.

Focusing on the study of gender balance in Brazil, we tackle the following research questions:

RQ1: How is gender balance distributed across different states in Brazil?

\footnotetext{
${ }^{1}$ https://www.statista.com/statistics/866227/facebook-user-share-brazil-gender/
} 
RQ2: How much does the gender balance vary across STEM and non-STEM majors?

RQ3: How does STEM gender balance behave in different demographic groups (e.g., education levels and age groups)?

Towards tackling these questions, our work presents a two-fold contribution: (i) a methodology proposal of assessing gender balance in STEM areas using Facebook Ads data, and (ii) a characterization of Brazil in terms of gender balance in STEM. Finally, we also correlate our methodology to assess STEM gender balance using Facebook data with other data sources, such as other Brazilian surveys [12, 24].

Our results suggest that even with a larger proportion of women on Facebook, STEM interests are still concentrated towards men in Brazil. The disparity is even more evident when we consider demographic attributes such as age and educational level, where the women seem to lose their interest in STEM areas. By analyzing these results it is possible to have insights into the impact of programs and initiatives to attract more women to STEM areas in different stages of educational level as well as age groups.

The remainder of the paper is organized as follows. Section 2 discusses related work. Then, Section 3 details our methodology of the Facebook data collection. Section 4 presents the metric used to assess gender balance using our dataset as well as the main results of gender imbalance in Brazil. Finally, Section 5 concludes the paper and presents future work.

\section{RELATED WORK}

In 2017, UNESCO has reported that women stand for $35 \%$ of all students enrolled in STEM-related fields in higher education [24]. Unfortunately, not only female participation is low but the attrition rate during and after college years is also high. Several studies focus on understanding what encourages women to follow STEM careers $[2,4,21]$. Our work aligns with other studies that quantify gender inequality using online data. However, as far as we know, this is the first study using online data (e.g., Facebook Ads) to quantify gender inequalities in STEM areas.

\section{STEM Gender Inequality Offline}

Some studies focused on strategies to increase women recruitment and retention in STEM areas. The main conclusions of these studies observed that a successful transition from schooling to university depends heavily on the support offered [2,3]. Moreover, the exposure of stereotyped media images of STEM professionals is pointed out as a possible factor for women under-representation in STEM fields $[4,21,22]$.

\section{Gender Gaps in Social Media}

Magno et al. [17] found that online inequality is strongly correlated to offline inequality. By analyzing data collected from Twitter and Google+, the authors conclude that women from less developing countries have a higher social status online (i.e., number of followers). The gender gap in Facebook was also contrasted with several indices of gender inequality (e.g., education, health, and economic opportunity) across multiple countries [7, 14]. These studies showed that social media has added value for women, lowering barriers to their access to information resources despite in some regions such as South Asia and sub-Saharan Africa, Internet access and basic digital skills are limited for women. Gender inequality is also larger in states with greater inequality in education and lower levels of social development such as in India [15]. Finally, LinkedIn's Advertising Platform is used to assess the gender skills gap in the US [10].

\section{Facebook Ads Demographic Data}

Recently, several studies have been using Facebook Ads API to monitor lifestyle interests [25], human mobility [20] as well as to measure the bias on news outlets audiences [19], disparities in Facebook adoption [9], and rural-urban inequalities [18]. Our work uses the same API to gather demographic data to measure gender inequality using Facebook interests as a proxy for the STEM audience.

\section{DATA}

In this section, we describe how we gathered data from STEM interests using Facebook Ads API as well as the audience across Brazilian regions.

Figure 1 shows the official population as well as the number of Facebook users across Brazilian states by gender. We see that the female audience is larger than the male audience in all Brazilian regions. According to the Brazilian Institute of Geography and Statistics (IBGE) ${ }^{2}$, the Brazilian population is composed of $49 \%$ of men and $51 \%$ of women. On Facebook Ads data, this imbalance is even more evident since more than $54 \%$ of the Facebook users are women. In fact, as found by Gil-Clavel et al. [9], women are more likely than men to engage with the Facebook platform.

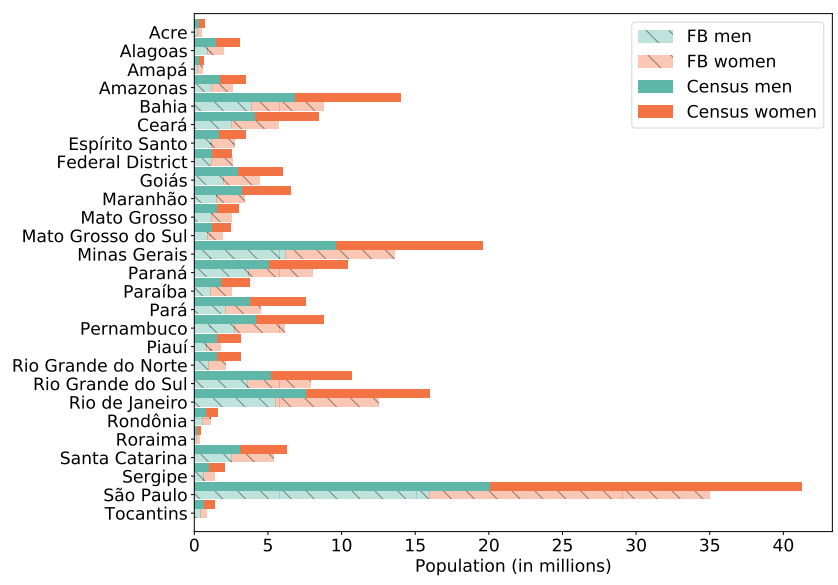

Figure 1: Population by gender in each Brazilian region. Darker colors show the official numbers according to the Brazilian Census (2010) and lighter colors show the audience on Facebook (data collected in September 2020).

In this work, we are interested in studying gender inequality in college majors, particularly STEM subjects. We address this problem

${ }^{2}$ https://educa.ibge.gov.br/jovens/conheca-o-brasil/populacao/18320-quantidade-dehomens-e-mulheres.html 


\begin{tabular}{|c|c|}
\hline Major group & College Majors \\
\hline Arts/Design (8) & $\begin{array}{l}\text { Architecture, Design, Graphic Design, Industrial Design, Interior } \\
\text { Design, Landscape Architecture, Music Education, Product Design }\end{array}$ \\
\hline Business/Entrepreneurship/Human Resources (10) & $\begin{array}{l}\text { Accounting, Management, Economics, Entrepreneurship, Finance, } \\
\text { Insurance, Marketing, Real Estate, Retail, Sales }\end{array}$ \\
\hline Communications (3) & Advertising, Journalism, Public Relations \\
\hline Computer Science/Information Systems/Technology (2) & Computer Programming, Computer Science \\
\hline Education (4) & $\begin{array}{l}\text { Early Childhood Education, Physical Education, Higher Education, } \\
\text { Secondary Education }\end{array}$ \\
\hline Humanities/Languages (6) & Gender Studies, History, Linguistics, Philosophy, Ethics, Theology \\
\hline Life Science (6) & Biochemistry, Biology, Botany, Ecology, Microbiology, Zoology \\
\hline Math/Physical Sciences (4) & Chemistry, Mathematics, Physics, Statistics \\
\hline Natural Resources/Sustainability/Environmental Science (5) & Astronomy, Aviation, Forestry, Geology, Oceanography \\
\hline Social Sciences (7) & $\begin{array}{l}\text { Anthropology, Cognition, Neuroscience, Geography, Psychology, } \\
\text { Social Work, Sociology }\end{array}$ \\
\hline
\end{tabular}

Table 1: College Majors Groups. Major groups in bold represent areas of knowledge containing STEM college majors.

by using Facebook users' interests in college majors as a proxy indicator of interest in those areas of study and subjects. Then, we evaluate how the Facebook audience is distributed across the STEM areas as well as the gender across different regions in Brazil.

The first step of our methodology for data collection consists of finding a list of the most common college majors. We have used a list published in Handshake ${ }^{3}$. Handshake is the industry-leading early-career network and career management platform which connects universities, employers, and students. The list provided by the platform consisted of 177 college majors classified along 15 areas of knowledge. The list of majors is populated by students when they import data to the website. Major groups represent a broader field of study developed in cooperation between the website and partner schools. We use the list of college majors to query the Facebook API to obtain estimates of the audience size for each major.

Facebook Marketing API ${ }^{4}$ allows users to obtain an estimated number of monthly active users for a proposed advertisement that matches given input criteria [16]. For that, the platform provides a list of demographic attributes, such as age, gender, home location, and interests that can be customized by the advertiser as the input query. Thus, after specifying the target public and before the ad is launched, advertisers are provided with the audience corresponding to the number of Facebook users that match with the target

\footnotetext{
${ }^{3}$ https://support.joinhandshake.com/hc/en-us/articles/360019970434-List-of-Major Groups

${ }^{4}$ https://developers.facebook.com/docs/marketing-apis
}

specifications. The users' interests, for example, can be informed by the user or inferred by Facebook based on user activities while posting or interacting with contents (e.g., liking, sharing, or updating status). Other attributes like age, gender, and location are explicitly declared by the users in their profiles.

After obtaining a list of 177 college majors from the Handshake site, we query Facebook Ads API, collecting the target audience interested in each college major. Focusing on Brazil, we also collect this audience based on users' demographic attributes such as home location, age, and educational level. We obtained 139 majors listed as interests of Facebook users and from that number 73 are categorized by Facebook Ads as being related to Education, Business and Industry, and Technology categories. We do not consider interests in other categories or with no specified category to avoid incorrect assumptions. In the following analysis, we consider the interest of Facebook users over the 73 interests related to college majors.

Table 1 shows all the 73 college majors grouped in 14 groups corresponding to areas of knowledge according to Handshake. Five of the 14 areas of knowledge contain STEM college majors. In total, we are considering 20 STEM college majors related to Technology, Engineering, Math/Physical Science, Life Science, and Environmental Science.

\section{MEASURING GENDER BALANCE}

In this section, we start by analyzing the gender gap across all the selected college majors in each Brazilian state. We also contrast 


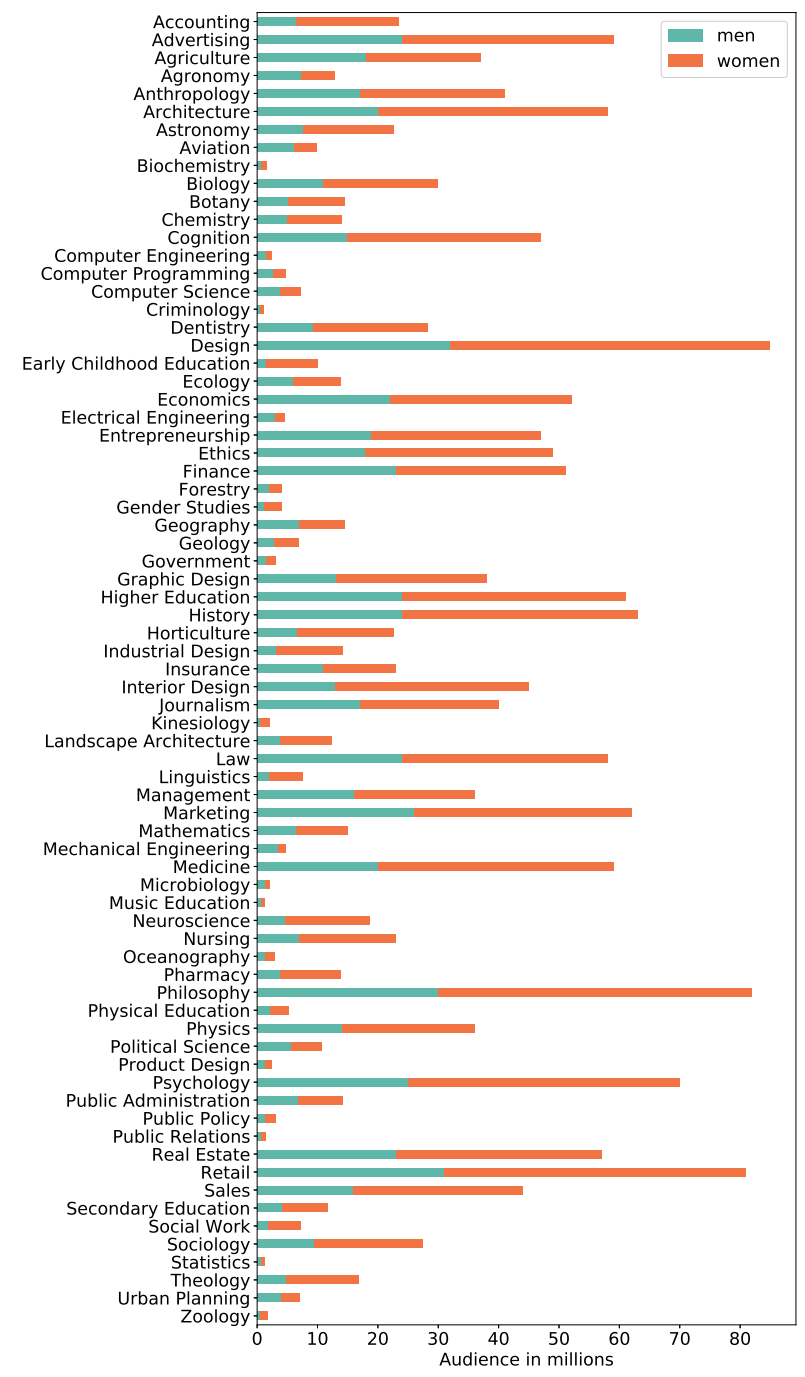

(a) Number of Facebook users (in millions) interested in each college major by gender.

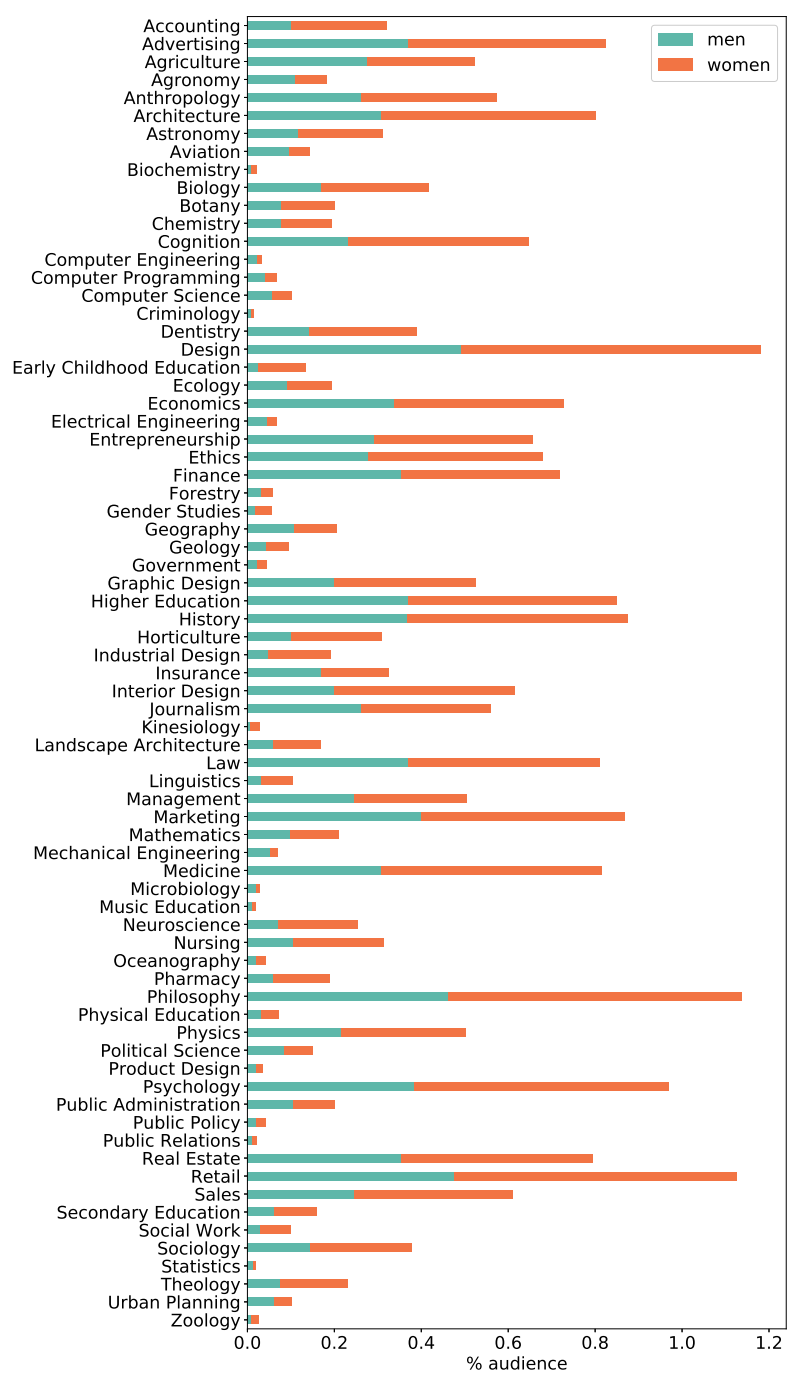

(b) Proportion of Facebook users interested in each college major by gender.

Figure 2: Facebook audience interested in some college majors in Brazil

gender balance across different education levels and age groups. For assessing the gender gap in our analysis, we use the Gender Balance metric used in Haranko et al. [10].

The gender balance score is defined in terms of the proportion of male and female Facebook users interested in a specific major. Before computing the metric, it is important to define the subset of the population we want to analyze. This population is obtained by using the combinations of various demographic attributes provided by Facebook Ads, for example, the subset of Facebook users with 20-35 years old in graduate school living in Brazil.

Considering the population $p$, the proportion of people of gender $g$ interested in a college major $m$ can be computed as shown in Equation 1.

$$
A_{p}(g, m)=\frac{\text { audience }_{p}(g, m)}{\text { audience }_{p}(g)}
$$

Basically, the $A_{p}(g, m)$ value in Equation 1 represents the fraction between the Facebook Ads audience of a specific gender $g$ in the population $p$ interested in the college major $m$ and the audience of this gender $g$ in the same population $p$. This normalization is important since we have imbalanced gender distributions (i.e., more female Facebook users than male) not only in Brazil as a whole but also in each state, as shown in Figure 1.

Among the 73 college majors, we show in Figure 2, the proportion of women and men in the population of Facebook users living in Brazil. Figure 2a reports the absolute audience number of men and women in each major while in Figure $2 b$ we present the same 
values normalized using Equation 1. Note that even with a biased population, we can see that for some majors, the proportion of men interested in them is higher than the proportion of women. For instance, majors related to Engineering, Technology, and Aviation have a higher proportion of men interested in them in comparison with the proportion of women. On the other hand, majors like Design, Retail, Ethics, and Psychology have a higher proportion of women.

For the rest of the analysis, we will consider the normalized audience to measure the Gender Balance (GB) of a major $m$ considering a defined population $p$. Equation 2 shows how to obtain the Gender Balance by using the normalized Facebook Ads audience.

$$
G B_{p}(m)=\frac{A_{p}(\text { male }, m)}{A_{p}(\text { male }, m)+A_{p}(\text { female }, m)}
$$

The possible values of Gender Balance are between 0 and 1, in which a value of 0.5 indicates gender parity and higher or lower values represent the male or female majority, respectively.

\subsection{Gender Balance in Brazil}

We start by analyzing Gender Balance across Brazilian states. Figure 3 shows the Gender Balance distribution over the 73 college majors in each Brazilian state. The bottom and top of the box correspond to the first and third quartiles, the band inside the box is the median, while dots are outliers. We observe that, for all the states, the median value is below the perfect Gender Balance $(G B<0.5)$, which means that $50 \%$ of the college majors have more female Facebook users interested in them. Observe that the vertical line is aligned with the third quartile of most Brazilian regions which means that there is a subset containing, approximately, $30 \%$ of the college majors which the proportion of men interested in them is higher than the proportion of women $(G B>0.5)$. We are particularly interested in analyzing the majors which extreme Gender Balance values. Moreover, we observe more outliers with high Gender Balance values $(G B>0.5)$, reflecting a male majority interested in the college major. Most of the outliers are related to Technology and Engineering majors, suggesting a lower presence of women interested in these majors.

We compute the gender distribution in each Brazilian state, comparing them across all the college majors. Figure 4 shows the Gender Balance distribution within each Brazilian state for each college major. Notice that the majority of college majors in which the proportion of men interested in them is higher than women $(G B>0.5)$ are considered STEM majors (filled in gray color). Most of these majors are part of the STEM subgroup related to Environmental Science, Engineering, or Computer Science (see Table 1). However, other STEM major groups like Life Science and Math/Physical Sciences have a low Gender Balance value, suggesting a higher proportion of women interested in them.

Notice that even in those majors classified as STEM, we can identify two distinct patterns between them. While college majors related to Environmental Science, Engineering, and Computer Science have more men interested in them, Life Science and Math/Physical are preferred by women.

Due to the difference in terms of gender balance across STEM college majors, the results can not be generalized to all areas of

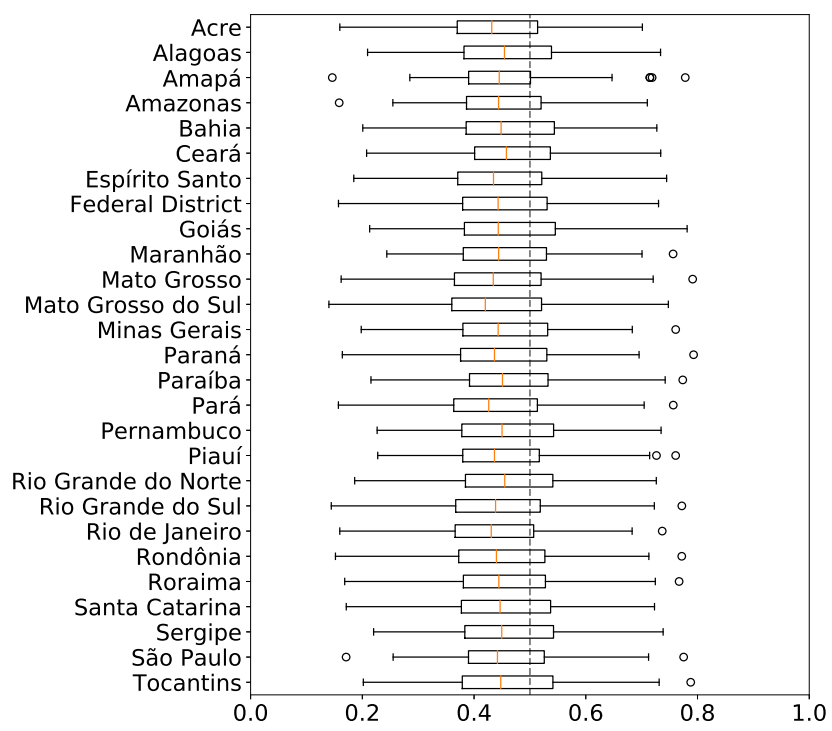

Figure 3: Gender balance (GB) distribution of Facebook users' interests in college majors for each Brazilian region. A GB of 0.5 indicates gender parity, and lower (higher) values represent the female (male) majority.

STEM. Thus the STEM majors can be subcategorized into one of the two subgroups. The first one includes college majors related to Life Science and Math/Physical, and the second one includes Environmental Science, Engineering, and Computer Science majors in which the female audience is underrepresented.

Considering non-STEM majors, there are more men $(G B>0.5)$ interested in majors such as Agriculture/Food/Horticulture and Civics/Government, Geography, Public Relations, Insurance, Product Design, and Music Education. Thus, we can notice that gender inequality is not a problem related only to STEM areas. Finally, we observe that most of the non-STEM majors in Brazil have a higher proportion of women.

We analyze the spatial distribution of Gender Balance values for some college majors across Brazilian states as shown in Figure 5. Figures 5a and 5b show the Balance Gender values for two selected majors: Mechanical Engineering and Early Childhood Education in each Brazilian region, respectively. As we notice in Figure 4, the Mechanical Engineering major has the highest values of Gender Balance (i.e., a majority of men interested), and that is consistently seen over all the Brazilian states. That suggests that there are no regional factors that affect the interest in that major. Finally, Early Childhood Education major has the lowest Gender Balance values (i.e., a majority of women interested). As the Mechanical Engineering, we also cannot see any regional differences in terms of the Gender Balance value for Early Childhood Education in Brazil.

Most of the boxplots in Figure 4 are completely located before or after the perfect Gender Balance value $(G B=0.5)$. In other words, there is no gender parity in terms of interest in most of the college majors since the interest is concentrated towards men or women.

However, there are majors in which the Gender Balance varies among states. An interesting case is the Ecology major, which has 


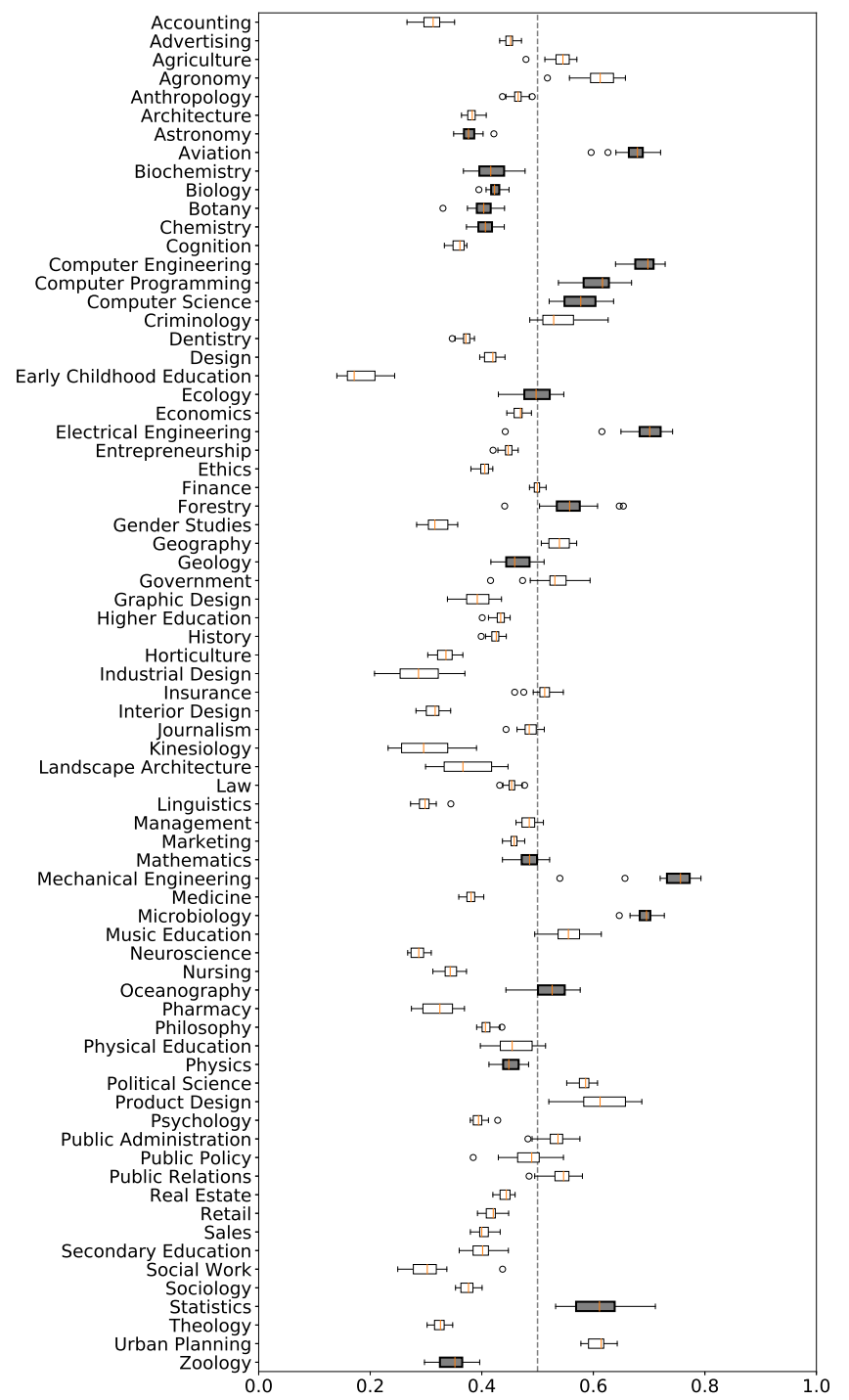

Figure 4: Gender balance (GB) distribution of Facebook users' interests in college majors across Brazilian regions. Boxplots representing STEM college majors are filled in gray color while non-STEM majors are in white. A GB of 0.5 indicates gender parity, and lower (higher) values represent the female (male) majority.

a balanced national proportion of men and women (median GB = 0.5 ), but disproportional GB values across Brazilian states. Figure $5 \mathrm{c}$ shows the Gender Balance value for Ecology in each Brazilian state. Notice that the Gender Balance value varies between 0.4 and 0.6 across Brazilian regions. The Southeast, South, and North are the regions where more women are interested in Ecology while in the Middle-West and Northeast the men seem to be more interested in this major.

\subsection{Contrasting Gender Balance with other demographic data}

In this section, we compare the data provided by Facebook Ads and the UNESCO Survey [24] results. Considering only the whole population in Brazil, we apply the gender balance analysis on demographic subgroups of this population in particular for education levels and age groups.

\section{Education Levels}

To assess the impact of education level in Gender Balance values, we consider three different subpopulations based on the educational subgroups provided by Facebook Ads: High School, College, and Grad School. Each subpopulation contains Facebook users who are currently enrolled or indicated their highest education level as one of the three categories.

Figure 6 shows the distribution of gender balance values per college major and education level. The figure shows the gender balance values for each major on a color scale, where redder ranges have a majority of women. For visual comparison, we also plot the values of Gender Balance for each major and education level.

In general, we observe that as the education levels increase the Gender Balance values also increase (i.e., reading the figure from the left to the right). Indeed, for some majors such as Statistics, Computer Engineering, Electrical Engineering, and Mechanical Engineering male dominance increases. Moreover, for most majors, especially STEM, the Gender Balance value increases between the transition from College to Graduate School (e.g., Computer Programming, Computer Science).

It is interesting to notice that even in areas in which women dominate, such as Education (except Early Childhood Education), that proportion decreases as the educational level improves. This is in agreement with that found by UNESCO's STEM and Gender Advancement (SAGA) project [11] in which the gender gap in STEM widens significantly in the transition from Bachelor's to post-graduate levels (e.g. Master's or Doctorate levels) as well as into research careers.

\section{Age Groups}

Next, we contrast Facebook users' age with their college major interests. We split the population into four subgroups: Adolescent (13 - 19 years), Early adulthood ( 20 - 39 years), Adulthood (40 - 64 years), and Maturity (65 years or more).

Figure 7 shows the Gender Balance value for each major considering the Brazilian population grouped by age. We observe the same pattern as the educational level where the proportion of female Facebook users interested in each major decreases as older as they are. Over their lifetime, women seem to lose even more interest in STEM majors such as Aviation and Mechanical Engineering.

For most majors, especially STEM, the Gender Balance value increases between the transition from Adolescent [13-19] to Early adulthood [20-39]. This result is consistent with that observed in the transition between High School and College where the female interest in STEM college majors decreases. 


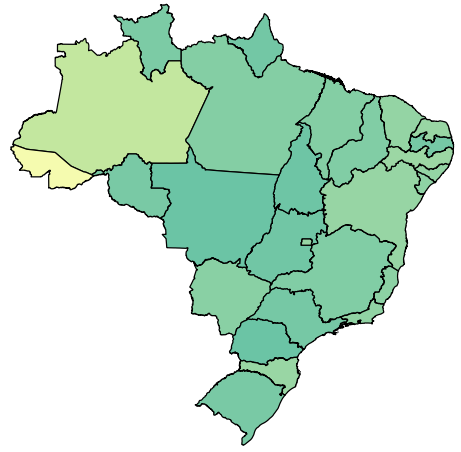

(a) Mechanical Engineering major.

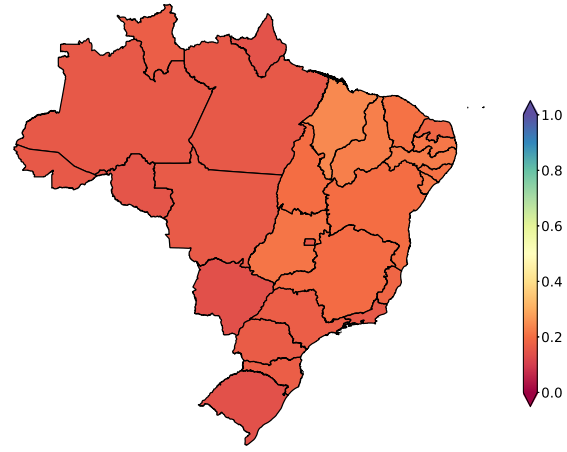

(b) Early Childhood Education major.

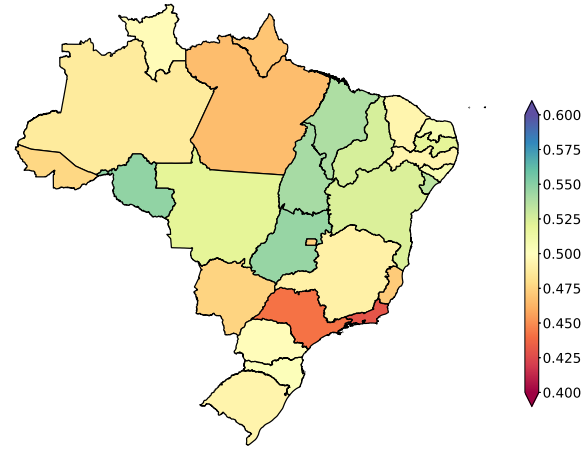

(c) Ecology.

Figure 5: Gender balance (GB) of Facebook users' interests in college majors across Brazilian regions. Hot (Cold) colors represent low (high) values of GB. A GB of 0.5 indicates gender parity, and lower (higher) values represent the female (male) majority.

\subsection{Limitations}

Facebook Ads works as a black box and the mechanisms behind how the tool infer demographic attributes from the offline world are not publicly known. This is a limitation of our method as we cannot evaluate the extent to which the collected data is reliable. In addition to this, the population of Facebook is known to be biased concerning gender, age, and other socio-demographic characteristics as previously discussed by some authors [1,9]. However previous studies have validated this kind of data with offline sources and shown promising results for digital gender inequality, migration, and cultural tastes [7, 20,25].

Moreover, we are also assuming that a significant part of Facebook users is publicly and honestly reporting their interests and personal information like age and educational level. That can be verified by comparing against external sources [1].

Also, we do not differentiate the importance of the interest in each major for the audience. In other words, we are assuming that the importance of each major is the same for all the users even if someone is interested in only one major and the others are interested in multiple ones.

We did not have success to obtain college majors using the Facebook attribute education_majors. Because of the scarcity of data using that attribute, we preferred to capture the audience in college majors using a more general interest attribute. We are not capturing only people who graduated in one of the college majors, but also people who expressed interest in that major on Facebook.

\section{DISCUSSION \& CONCLUSION}

This paper explores the use of Facebook Ads data to assess Gender Balance in STEM college majors. As a case study, we apply our methodology focusing on the Brazilian population. Brazil is an interesting case, where the female population is larger than the male one and most of the researchers are women. Nevertheless, the proportion of men interested in some majors is higher than the proportion of women, particularly among STEM majors related to Environmental Science, Technology, and Engineering.
Our analysis provides a general picture of how gender inequality is present in STEM majors as well as their distribution across different regions in Brazil. In sum, the Gender Balance does not vary so much between Brazilian regions considering the same major. Ecology, for example, is an exception since the Gender Balance varies from a state to another. It is also interesting to compare how the majors can differ from each other. Some of them are completely dominated by women and others by men independently of the region, like Early Childhood Education and Mechanical Engineering, respectively.

We also assess the impact of educational level and age on the interest in majors. As reported by official data in Brazil, as women become older or have higher educational levels, their interest in STEM areas decreases. It is important to point that STEM majors must be analyzed separately as they present diverse ranges of Gender Balance values and are also influenced by age and educational level. While majors related to Environmental Science, Engineering, and Computer Science have more men interested in them, Life Science and Math/Physical seems to be more preferred by women.

In general, the results are similar to that we obtain by official statistics, however by using Facebook Ads, we may overcome some limitations by spending lower resources to collect huge amounts of data in a short time. Moreover, the focus on Brazil contributes to the literature of gender imbalance studies providing statistics about geographic regions that were not studied before.

Finally, the most important result is that now we can identify the critic's points related to the age and the educational level when more girls and women give up the STEM area. By analyzing these results, it is possible to have insights regarding the impact of programs and initiatives to attract more women to STEM areas in different stages of educational level as well as age groups.

Our work adds value to other gender inequality studies as well as present a methodology that can be extended to other countries or different granularities (e.g., cities in the same state). As future work, we expect to continue validating our methodology by extending to other countries as well as implementing an online tool that could provide useful insights into STEM gender balance. 


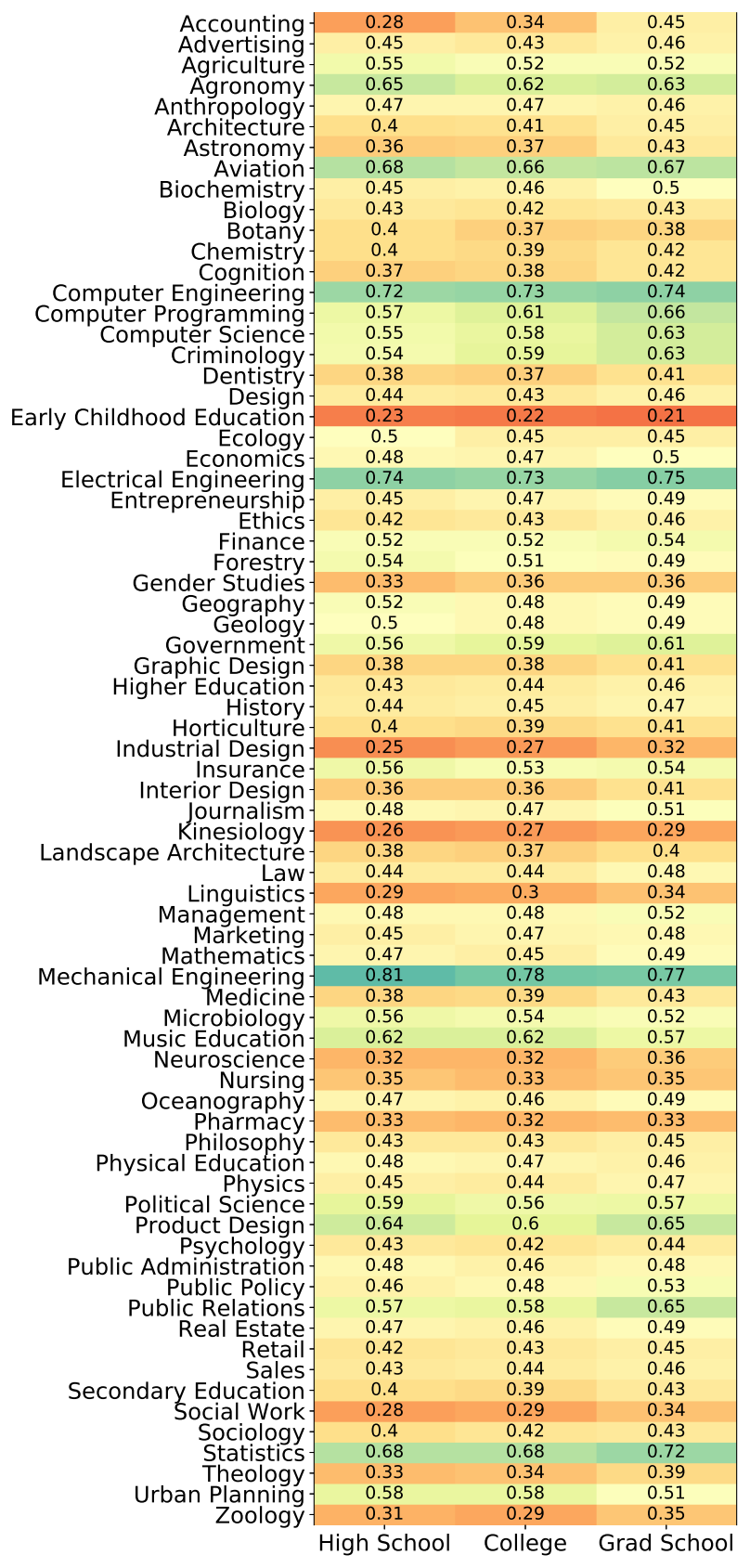

Figure 6: Gender Balance (GB) distribution of Brazilian Facebook users' interests in college majors by Education Statuses.

\section{REFERENCES}

[1] Matheus Araujo, Yelena Mejova, Ingmar Weber, and Fabricio Benevenuto. 2017 Using facebook ads audiences for global lifestyle disease surveillance: Promises and limitations. In Proceedings of the 2017 ACM on Web Science Conference. 253257.

[2] Carmen Botella, Silvia Rueda, Emilia López-Iñesta, and Paula Marzal. 2019. Gender Diversity in STEM Disciplines: A Multiple Factor Problem. Entropy 21, 1 (Jan

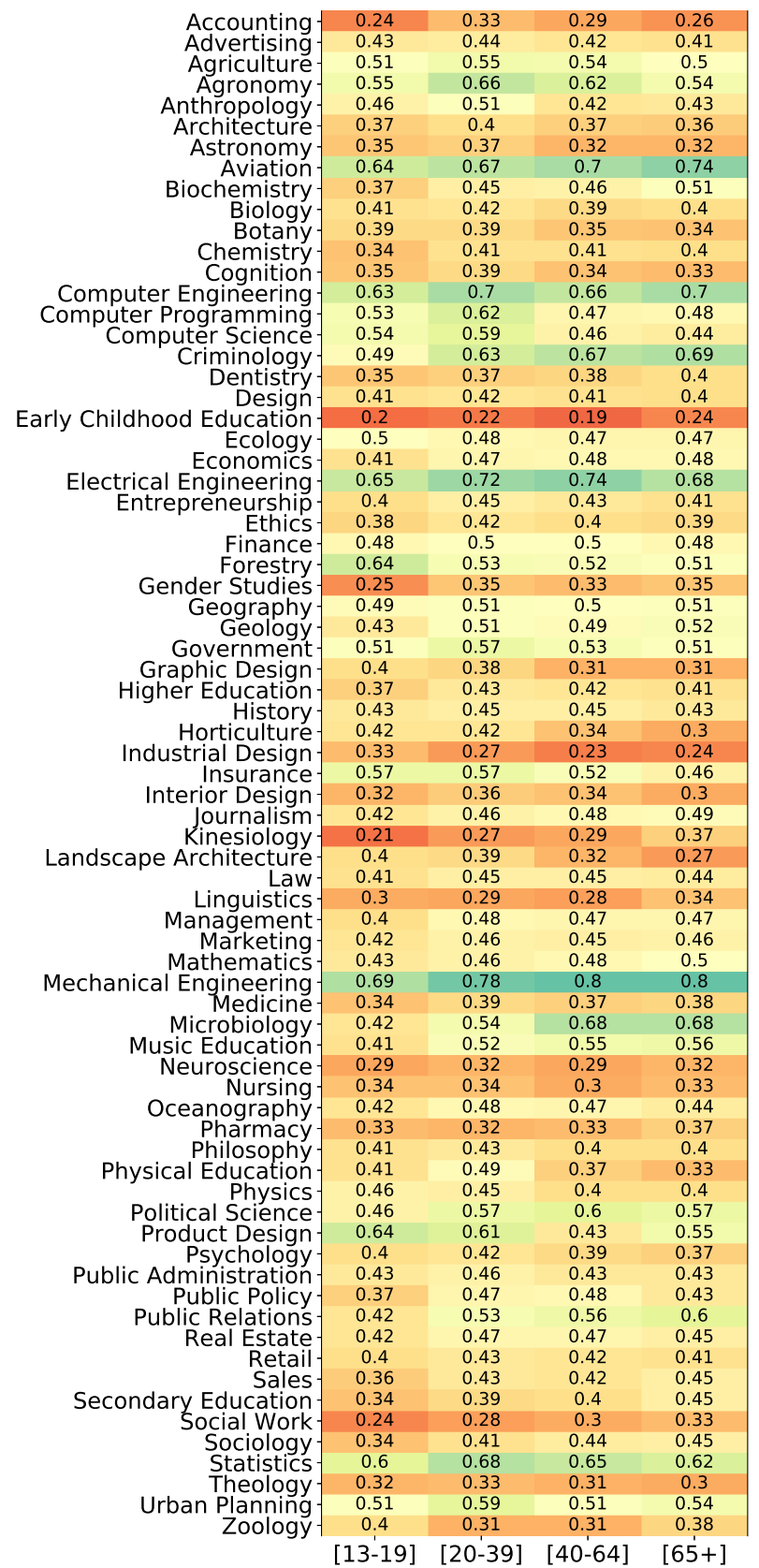

Figure 7: Gender Balance (GB) distribution of Brazilian Facebook users' interests in college majors by Age Group.

2019), 30. https://doi.org/10.3390/e21010030

[3] Michael Christie, Maureen O Neill, Kerry Rutter, Graham Young, and Angeline Medland. 2017. Understanding why women are under-represented in Science, Technology, Engineering and Mathematics (STEM) within Higher Education: a regional case study. Production 27 (00 2017).

[4] Beatriz Clewell and Patricia Campbell. 2002. Taking stock: Where we've been, where we are, where we're going. Journal of Women and Minorities in Science and Engineering 
[5] Bernhard Ertl, Silke Luttenberger, and Manuela Paechter. 2017. The Impact of Gender Stereotypes on the Self-Concept of Female Students in STEM Subjects with an Under-Representation of Females. Frontiers in Psychology 8 (2017), 703. https://doi.org/10.3389/fpsyg.2017.00703

[6] World Economic Forum. 2020. Global Gender Gap Report. http://www3.weforum org/docs/WEF_GGGR_2020.pdf. Accessed: 2020-09-08.

[7] David Garcia, Yonas Mitike Kassa, Angel Cuevas, Manuel Cebrian, Esteban Moro, Iyad Rahwan, and Ruben Cuevas. 2018. Analyzing gender inequality through large-scale Facebook advertising data. 115, 27 (2018), 6958-6963.

[8] A. García-Holgado, J. Mena, F. J. García-Peñalvo, J. Pascual, M. Heikkinen, S Harmoinen, L. García-Ramos, R. Peñabaena-Niebles, and L. Amores. 2020. Gender equality in STEM programs: a proposal to analyse the situation of a university about the gender gap. In IEEE Global Engineering Education Conference (EDUCON).

[9] Sofia Gil-Clavel and Emilio Zagheni. 2019. Demographic differentials in Facebook usage around the world. In Proceedings of the International AAAI Conference on Web and Social Media, Vol. 13. 647-650.

[10] Karri Haranko, Emilio Zagheni, Kiran Garimella, and Ingmar Weber. 2018. Professional Gender Gaps Across US Cities.

[11] Sophia Huyer. 2015. Is the Gender Gap Narrowing in Science and Engineering? UNESCO Science Report: Towards 2030. Available at http://unesdoc.unesco.org/ images/0023/002354/235406e.pdf and accessed: 2020-09-15.

[12] INEP. 2018. Sinopses Estatísticas da Educação Superior - Graduação. http://portal inep.gov.br/web/guest/sinopses-estatisticas-da-educacao-superior. Accessed 2020-09-14.

[13] Elsevier Research Intelligence. 2017. Gender in the Global Research Landscape. https://www.elsevier.com/_data/assets/pdf_file/0008/265661/ ElsevierGenderReport_final_for-web.pdf. Accessed: 2020-09-08.

[14] Ridhi Kashyap, Masoomali Fatehkia, Reham Al Tamime, and Ingmar Weber. 2020. Monitoring global digital gender inequality using the online populations of Facebook and Google. Demographic Research 43, 27 (2020), 779-816.

[15] Ridhi Kashyap, Masoomali Fatehkia, Reham Al Tamime, and Ingmar Weber 2020. Monitoring global digital gender inequality using the online populations of Facebook and Google. Demographic Research 43 (2020), 779-816.
[16] Michal Kosinski, Sandra C Matz, Samuel D Gosling, Vesselin Popov, and David Stillwell. 2015. Facebook as a research tool for the social sciences: Opportunities, challenges, ethical considerations, and practical guidelines. American Psychologist 70, 6 (2015), 543.

[17] Gabriel Magno and Ingmar Weber. 2014. International Gender Differences and Gaps in Online Social Networks. In International Conference on Social Informatics.

[18] Daniele Rama, Yelena Mejova, Michele Tizzoni, Kyriaki Kalimeri, and Ingma Weber. 2020. Facebook Ads as a Demographic Tool to Measure the Urban-Rural Divide. In Proceedings of The Web Conference 2020 (WWW'20).

[19] Filipe Ribeiro, Lucas Henrique, Fabricio Benevenuto, Abhijnan Chakraborty, Juhi Kulshrestha, Mahmoudreza Babaei, and Krishna Gummadi. 2018. Media Bias Monitor: Quantifying Biases of Social Media News Outlets at Large-Scale. In International Conference on Web and Social Media.

[20] Spyridon Spyratos, Michele Vespe, Fabrizio Natale, Ingmar Weber, Emilio Zagheni, and Marzia Rango. 2019. Quantifying international human mobility patterns using Facebook Network data. PLOS ONE 14, 10 (10 2019), 1-22.

[21] Jocelyn Steinke, Maria Lapinski, Marilee Long, Catherine Van Der Maas, Lisa Ryan, and Brooks Applegate. 2009. Seeing Oneself as a Scientist: Media Influences and Adolescent Girls' Science Career-Possible Selves. Fournal of Women and Minorities in Science and Engineering 15, 4 (2009), 279-301.

[22] Jocelyn Steinke and Paola Paniagua Tavarez. 2018. Cultural Representations of Gender and STEM: Portrayals of Female STEM Characters in Popular Film 2002-2014. International fournal of Gender, Science and Technology 9, 3 (2018), 244-277.

[23] Alan Tovey. 2017. Why STEM needs fresh ideas to bring about the fourth Industrial Revolution. https:/www.telegraph.co.uk/education/stem-awards/ stem-hq/industry-needs-experts/. Accessed: 2020-09-14

[24] UNESCO. 2017. Cracking the Code: Girls' and Womens' Education in Science, Technology, Engineering and Mathematics (STEM). https://unesdoc.unesco.org/ ark:/48223/pf0000253479. Accessed: 2020-08-22.

[25] Carolina Vieira, Filipe Ribeiro, Pedro de Melo, Fabricio Benevenuto, and Emilio Zagheni. 2020. Using Facebook Data to Measure Cultural Distance between Countries: the Case of Brazilian Cuisine. In The Web Conference. 